\title{
Linguistic and Epistemology Challenges in Research Writing: An Exploratory Study of Chinese Graduate Students' Academic Writing Experiences
}

\author{
Fei Wang \\ Department of English, Anhui Normal University, Wuhu, China
}

Email address:

Fwang78@mail.ahnu.edu.cn

\section{To cite this article:}

Fei Wang. Linguistic and Epistemology Challenges in Research Writing: An Exploratory Study of Chinese Graduate Students' Academic Writing Experiences. International Journal of Language and Linguistics. Vol. 7, No. 6, 2019, pp. 245-254.

doi: $10.11648 /$ j.ij11.20190706.11

Received: February 25, 2019; Accepted: July 2, 2019; Published: October 10, 2019

\begin{abstract}
The purpose of this grounded theory study was to examine the difficulties faced and strategies used by Chinese graduate students with English academic writing at an American university. Eight graduate students majoring in humanities and social sciences at different stages of their graduate studies were interviewed. The interview data illustrated the types of difficulties that these students encountered and the types of coping strategies they used in the process of adapting to the requirement of specific disciplinary written discourses. Difficulties and problems varied across the curriculum and the individuals. Some common problems included insufficient linguistic knowledge, being unfamiliar with academic writing conventions and gaps in the epistemological assumptions between U.S. and China's academia. One of the biggest gaps is lack of critical thinking skills among Chinese students and different attitudes towards verification in writing. These difficulties and problems reflect the complexity of writing as a socially constructed activity that requires necessary linguistic knowledge as well as familiarization with cultural models, i.e., ways of thinking, believing and valuing that are associated with the disciplinary discourses. The results of the study suggest that this group of Chinese graduate students had received limited training in English academic writing before they came to U.S and they brought with them to the U.S. classrooms writing experiences that at times differ from the writing conventions of the American academia and, therefore, need assistance in order to successfully adjust to the new academic environment. This study also showed that there is not enough social help for those international graduate students. For most of them, adjusting to the U.S. academic written discourse is mainly a trial-and-error process. Therefore efficient social help from the peers, professors and curriculum is needed.
\end{abstract}

Keywords: Academic Writing Discourse, EAL Writers, Argumentative Writing, Critical Thinking

\section{Introduction}

In 2015, around 36 per cent of doctorate recipients in US have been international students, of which Chinese studentsaccounted for almost 50 percent [27]. In light of the ever growing representation of nonnative English speaking (NNES) graduate studentsin the English speaking academies, a substantial body of studies has been devoted to the challenges encountered by NNES students in learning to write research papers $[3,4,23]$. Compared to the large proportion of Chinese students in U.S. graduate programs, the number of studies specifically focusing on the writing experiences of Chinese students have been relatively small.
In particular, writing experiences of Chinese students in social sciences have largely been ignored. Unlike sciences, social sciences majors are more language-dependent [5] and often have differing epistemology across sociocultural contexts. In addition, Chinese studentsgenerally lack the training of academic thinking skillsdue to the test-oriented education system and sociocultural factors. Most of them are unprepared for disciplinary writingand need help during their transition from test-oriented English short essay writing to research writing [21]. However, the few existing studies on Chinese EAL students mainly focus on experienced student writers writing for publications in sciences [20-22]. Writing experiences of Chinese student writers in social sciences have 
largely been neglected. In order to address this research gap, this study investigated - through interviews - eight Chinese graduate students' perspectives on their writing challenges in social sciences at a research intensive university in America.

\section{Insights from the Literature}

\subsection{English as an Additional Language (EAL) Writers, Perceptions of Linguistic Barriers}

Writing in a second language is certainly more laborious [33]. Many EAL novice writers see their difficulties mainly as linguistic problems $[2,18,28]$, such as word-choice or sentence-level grammar. This assumption of the primacy of language [16] in academic writing is especially popular among EAL novice writers in social sciences. They attributed their writing challenges mainly to the NNES status.

Many EAL student writers developed a low self-efficacy in writing English [2] due to their frustration with linguistic limitations. Excessive attention to language deficiencies functions to "demoralize"[16] EAL novice writers when their primary challenge is actually beyond the surface language. Theyfelt less able as a learner [25]. Some were even discouraged to pursue further academic English publications [37]. This language deficiency view lessens writers' zeal to do better. The current study joins in this line of research tofurther explore how the linguistic challenges are perceived bythe Chinese EAL writers in social sciences.

Mohan and Lo [26] defined surface language problems as an developmental issue, which means that the language proficiency would improve as long as EAL writers keep practicing. Recent flourishing publications by non-Anglophones in English social science journals support the view that language limitation is not "terminal" [16].

\subsection{EAL Students' Epistemology Challenges}

Higher education academic writing requires more than just improving linguistic abilities [17]. "Appropriateness" of students' writing in a specific community has more to do with issues of epistemology than with surface features of form [19]. But little research addresses the epistemology gaps between China's social sciences writing and its American counterpart [37]. The epistemology challenge encountered by Chinese social sciences studentsis a much neglected research area.

The scant studies on epistemology differences between China and U.S. mainly focus on the issues of critical thinking, making attributions, and using empirical data [5, 30, 37]. For example, Zhang [37] found that the prevalent influence of 'Marxism' and 'Maoism' made Chinese students feel at a loss when they were exposed to a variety of diverse social science philosophies in the west and one participant shared that she has been taught that everything she read at school is right since she was a child. In one study [5], one social science professor participant upheld critical thinking skills and argumentative writing as the most important skills for graduate students. The professor felt that EAL students tended to be underprepared in this area.
Another fundamental, yet generally overlooked challenge for EAL novice writers is learning argumentative writing [14, $31,32,34]$. Both native-speaking and EAL student writers need to learn to formulate, to verify and to evaluate arguments in research writing. Even though this ability to argue is rooted in human nature [34], the actual abilities and forms of arguing can vary with individuals due to different sociocultural contexts. EAL students move to L2 writing already possessing culturally shaped notions of argumentative writing from their L1 education $[14,38]$. They might have insufficient education about argumentative writing. They might hold different beliefs of what counts as a valid piece of argument or evidence. It is, therefore, necessary to understand EAL novice writers' challenges through looking at their preparation with argumentative writing from their prior education. Given the scarcity of research on how students' native language and cultural background shape their L2 argumentative activities, this study aimed to explore how Chinese students develop argumentation and the related sociocultural contexts.

\subsection{English Education in China}

Students in China wrote English essays primarily to get high scores to pass high-stakes tests [30]. The 'teach to the test' system does not leave much space for English teachers to train students' academic thinking skills, such as independent, analytical and critical thinking skills. In order to get high scores, students had to follow certain safe models, instead of expressing creative and critical ideas. Students were told what to write and how to write in test preparation. Independent and critical thinking are not valued in English writing assessment in high-stakes English test in China.

Lack of thinking training is also deeply rooted in the tradition of China's social science education. Students are simply taught to memorize texts. Critiquing social issues is not encouraged. Students are taught to resort to citing famous people, old saying and flowery diction, rather than independent and critical thinking, to get high scores in English writing. Hence, Chinese students felt at a loss when they found that their expertise of test taking and formulaic writing are not valued in their graduate programs in U.S. [30]

Grammar-translation English teaching practice remains the dominant method of English language teaching in China. This emphasis on the accuracy of word choice and sentence grammar naturally leads to students' excessive concerns about the surface language problems [28, 36]. Together with the great impact of high-stakes test, Chinese students have to be constantly highly aware of their language accuracy in writing, instead ofdeveloping thinking skills and expressing ideas.

These insights from the literature suggest that academic writing challenges encountered by EAL graduate students include both linguistic and epistemology differences. While linguistic barriers persist for EAL students across disciplines, linguistic barriers and epistemology differences seem to play a more salient role in causing challenges for social science majors. Given the scarcity of research specifically focusing on Chinese social science students' writing challenges, this study extends the literature by exploring how eight Chinese EAL 
graduate students in social sciences view the language and epistemology challenges in academic writing. Sociocultural factors causing their challenges were also discussed. The study explored two research questions:

1) How do Chinese EAL graduate students in social sciences view the linguistic and epistemology challenges in research writing?

2) What are the sociocultural factors leading to these challenges?

\section{Theoretical Framework}

Gee's theory of D/discourse was originally developed to investigate relationship between language learning, social identity, and social contexts in first language acquisition. Given that recent L2 writing research [15] has recognized the need to explore the sociocultural contexts in which academic writing takes place, Gee's theory provides a tool for understanding EAL students' writing experiences.

Gee defined Discourse with an upper-case Das

... a socially accepted association among ways of using language, other symbolic expressions, and artifacts, of thinking, feeling, believing, valuing and acting that can be used to identify oneself as a member of a socially meaningful group or "social network" (p.131).

Thus, Gee's Discourse not only integrates ways of talking, listening, writing, and reading, but also integrates ways of thinking, believing and valuing into linguistic patterns recognizable to a social group [10-13]. According to this concept, disciplinary writing is one type of Discourse, the acquisition of which requires familiarization with the specific ways of thinking and valuing in that discipline as well as the surface linguistic elements that are associated with it. Academic thinking usually includes producing ideas and evaluating ideas, which involves analytic, critical and creative thinking skills [29]. Sociocultural contexts of the disciplinary writing must also be carefully considered in exploring student writers' challenges in learning a new disciplinary Discourse.

Within each disciplinary Discourse, members share common ways of thinking and uses of language. EAL student writers are involved in at least two different Discourses: L1 Discourse and L2 Discourse. Challenges in acquiring the new L2 Discourse arise when there is "conflict and tension between the values, beliefs, attitudes, interactional styles, uses of language, and ways of being in the world which two or more Discourses represent" [8].

Language, therefore, is seen as one of the constituent elements of disciplinary Discourse. Gee defines discourse with a lower case d as:

... any stretch of language (spoken, written, signed) which "hangs together" to make sense to some community of people who use that language... making sense is always a social and variable matter: what makes sense to one community of people may not make sense to another [9].

A specific discourse is made up of all of the language bits and uses that are associated with a specific Discourse. Given the social nature of Discourse, a discourse is also a social language [13]. In a disciplinary Discourse, social languages are reflected in different patterns of vocabulary and syntax. Social languages also connect to specific social activities and to specific socially situated identities associated with a Discourse $[10,11]$. This suggests that EAL student writers need to learn how to use specific grammatical and lexical means to do the specific social activities and to represent the specific identities involved in being a member of that disciplinary Discourse.

The specific social activities and identities embedded in the discourse often relate to its cultural and historical contexts. In other words, the specific discourse has its 'discursive histories' [11]. Gee explained the discursive histories as:

Words have histories.... they [words] have circulated through other Discourses and within other institutions.... Words bring with them as potential situated meanings all the situated meanings they have picked up in history and in other setting and Discourses. ([11], p. 54)

In disciplinary writing, EAL students' cultural and educational background constituted their discursive history. The way they write can be traced back to their prior social and educational contexts.

Gee's theory of D/discourses provides a tool to understand EAL student writers' challenges. Language use merely exists as one component within the larger construct of a Discourse [24]. In order to become a member of the new disciplinary Discourse, EAL student writers have to learn the language use, i.e., the lower-case discourse as well as the patterns of thinking, believing and valuing underlying the Discourse situated in a sociocultural context. If there is a conflict between the required values or identities of two distinct Discourses, acquisition of the new Discourse may be difficult.

\section{Methods}

\subsection{Research Tradition}

This studyadopted grounded theory approach because the study intended to seek for the "plausible relationships" [35] among the constructs of Chinese students' writing challenges and their sociocultural causes. Findings are presented in the form of theoretical propositions [7].

\subsection{Context and Participants}

The study was conductedata major research university in the northeast of the United States. Eight Chinese graduate students who majored in education, communication, American studies, history, and library management participated in the study after signing the informed consent forms. The study followed theoretical sampling [6] to select participants to help the researcher best form the theory propositions. In order to better interpret students' writing challenges from an insider's perspective, the researcher chose participants who shared the same first language, i.e., Chinese. Participants' disperse majors also "provided important contextual information useful in the axial coding phase of research"([6], p.114). These participants were considered as 
advanced English learners because they obtained high scores in Graduate Record Exams to be admitted to US graduate programs. But they were also novice academic writers since most of them were at the early stage of doctoral programs. The following table shows a brief description of the eight interviewees.

Table 1. A profile of the participants.

\begin{tabular}{llllll}
\hline Name & Gender & Age & Program & Current status & Years they have studied in U.S. \\
\hline Yan & F & 26 & Ph.D.inEducation & Second year doctoral student & 2 \\
Teng & M & 27 & Ph.D.in Education & Second year doctoral student & 2 \\
Yun & F & 29 & M.A. in Communication & Second year master student & 2 \\
Jie & F & 27 & Ph.D. inEducation & Third year doctoral student & 3 \\
Liang & M & 29 & Ph.D. in Education & Third year doctoral student & 3 \\
Ray & M & 25 & Ph.D. in Library Management & First year doctoral student & 2 \\
Hong & F & 29 & M.A. in American Studies & Second year master student & 2 \\
Jiang & M & 30 & Ph.D. in History & Fifth year doctoral student & 5 \\
\hline
\end{tabular}

\subsection{Data Collection}

The study drew upon face-to-face in-depth interviews with eight participants. When I started to interview, I did not set a fixed number of interviewees. I decided to stop interviewing at the 'saturation' stage ([6], p.57) when I expected that not much new information was coming out from more interviews The interview questions seek to elicit students' views on the following aspects: 1) views about linguistic challenges; 2) views about epistemology challenges; and 3) views about preparations with academic writing. Interviews were conducted either in English or Chinese, depending on the interviewee's choice. All interviews were audio-taped and transcribed verbatim. The Chinese interviews were translated into English in transcribing. Each interview lasted around 30 minutes. Each line of transcripts was numbered for reference.

\subsection{Data Analysis}

Data analysis adopted the standard format required by grounded theory study: initial coding, axial coding and selective coding or forming theoretical propositions ([6] p.57). The two topical research questions (a. What kinds of writing problems do they have? $\mathrm{b}$. How are they prepared with English academic writing in China?) guided theinitial coding. I made annotations to the data in the margins as I read. Based on the margin notes, I developed initial ten categories: types of problems, types of papers they write, differences between Chinese and English academic writing, important elements in academicwriting, writing strategies, how to seek help, academicwriting's role, professors' feedback, acculturation process and suggestions they give to new students.

Then I look for data to 'dimensionalize' the category ([6], p. 57), i.e., enriching each category with relevant data that fell in the corresponding category and noted down their line numbers for future retrieval. At the axial coding stage, I merged, deleted and reorganized those ten initial categories into three broader categories: viewsof language challenges, views of epistemology challenges and causal factors that shaped their challenges. Finally, integrating the earlier categories in selective coding stage, I developed three propositions in answering for the research questions.

\section{Findings}

The following sections are organized by three propositions: 1). Although language was not viewed as a primary concern, EAL status demoralized EAL writers; 2). Thinking skills required in producing, verifying and critiquing arguments constituted the fundamental challenges for EAL writers; 3). Students attributed writing challenges to epistemology gaps in social sciences and insufficient preparation in doing research and research writing.

\subsection{Although Language Was Not Viewed as a Primary Concern, EAL Status Demoralized EAL Writers}

Keen awareness of linguistic shortcomings persisted for these EAL students. Their concern was not grammatical, but rhetorical, i.e., how towrite "beautiful English in American eyes" (Ray, line 86). The sense of rhetorical inabilities was strong among students who were writing qualitative research, which uses words as the most important device to depict human beings' lived experiences. Yan's main obstacle was how to "polish up sentences and be idiomatic" (Yan, line 25). She had no problem in using graph to develop her argument, but was frustrated with narrating and describing. She felt her plain English weakened or even distorted her original emotions. Liang, who was also doing qualitative research, complained that his English was not "powerful" (Liang, line 90) enough to attract American readers. As he said,

Because I am doing qualitative research, I have some problems in writing findings. For example, how to express themes in accurate academic language is not easy. Native speakers can use very powerful words and powerful rhetoric to form their themes, but [as second language learners], we are disadvantaged in this aspect. Although we have good ideas, it's difficult to put them into words in a way we want to. For example, once we were asked to give a name to a course package. It was really difficult. How could I find out an English word that is attractive to readers and has strong rhetorical effects? But those native speakers came up with many wonderful phrases which were really beyond our language ability.

(Liang, lines 88-94)

Both Yan and Liangsensed their rhetoric limitations. In 
Yan's eyes, writing qualitative research was like"writing a novel" (line 32). When Yan was reading the touching stories written by famous qualitative researchers, like Judith Butler, she felt that she would never be able to write like her. This sense of rhetoric disadvantage was also mentioned by other participants. They felt even more frustrated because they had not figured out an effective way to improve their rhetoric ability. They saw this rhetoric challenge as something "beyond their language ability" (Liang, line 94).

\subsection{Thinking Skills Required in Producing, Verifying and Critiquing Arguments Constituted the Fundamental Challenges}

\subsubsection{Challenge in Producing Ideas: Learning to Use Literature}

Although participants recognized the rhetoric challenges, none of themsawconsideration of styles as fundamental to academic writing. They believed that how to create and develop ideas is the core. As Teng said, "Native English speakers can polish up your language very easily, but they can not help you with your ideas.... Ideas can only be developed by yourself." (lines 73-76) Jie's mentor told her that international students shall focus on developing ideas, instead of worrying too much about language style.

Firstly, they were all frustrated with their poorly-prepared reading skills: slow in reading and struggling tograsp general ideas. Finishing reading assignments posed a big challenge for all. Fang, a fifth year doctoral student in history, recalled:

In China, you know, we also had three courses one semester. But we only used one textbook for one course for the whole semester and we even couldn't finish that one textbookHere is one book one week. There are 12 weeks one semester. So we read 12 books one semester. At first, I couldn't finish reading the whole book in one week. I just picked the introduction and conclusion. I even couldn't finish reading the introduction. (lines 63-69)

Since they started graduate study in U.S., they realized the importance of extensive reading. Students were not used to reviewing extensive literaturebefore they wrote. Generally, Chinese graduate studies don't have rigorous reading requirements. Teng believed that literature reading process was more important than the writing per se, because reading "generates new ideas to write about" (Teng, line 101)." If you read only one article, you will be biased by it. But if you read 100 articles, you will know various perspectives and you can generate new ideas." (Teng, lines 97-101)

Secondly, some students reported that synthesizing literature in an analytic and logic way was challenging. After reading literature, participants needed to analyze various thoughts and synthesize them with logic in order to generate the new topic they wanted to write about. Ray felt most challenged with justifying his proposed model. He needed to analyze, synthesize and critique previous studies to justify his proposed model. As he said:

You have to read a lot of studies and try to analyze, summarize and synthesize all those studies and then you need to justify your model. This justification process takes a lot of time to write. You have to write clearly why you think this model is good, why that model is not efficient. If you want to do some modifications to some existing models, you need to provide justifications why such modifications are needed. Anyway, when you put forward your own ideas and theories, you need to justify why your theories are right and you need to convince readers of your theories. You have to justify when you add or delete a variable in the previous models... The most difficult part is the justification of your new theories and new model. This part needs logic.

(Ray, interview, lines 120-130)

Thirdly, Chinese students also learned to make attributions to other researchers in formulating new topics. Learning to cite others' works in supporting the proposal was a big progress for many of them. Most of the interviewees acknowledged they were not used to rigorous citations, since many disciplines in China do not have this tradition. Fang said that Chinese scholarly writing in classical history"had no citations, no footnotes and no endnotes" (lines 71-72). As Fang recalled:

In China, we were not strict about citations, footnotes or endnotes.... Chinese classical history had no citations, no footnotes or no endnotes.... If the authors have some idea, they just write it regardless of whether this topic has been researched or not. After we came to America, we understand that we need to read others' studies before we start to write. This is a big progress for us. ( lines69-76)

Fang's words showed that epistemology difference caused his challenge in using citations. In fact, several participants mentioned their learned awareness of making attributions to other studies in producing new topics. Yun said that she used to write about whatever idea in her mind without bothering literature search. Now she learned that she needed to go to the library to find out related references first.

In sum, this group of Chinese EAL writers encountered challenges inlearning to use literature for writing. Various thinking skills required in reviewing literature, such as analyzing, synthesizing, justifying, critiquing and attributing, were perceived asfundamental challenges for them.

\subsubsection{Challenge in Developing Argumentation: Learning to Use Data}

All participants realized that developing argumentation is more important than the language per se. As Teng said, "In my opinion, the most important thing in academic writing is not the language per se, but your argument and how you use your evidence to support your argument." (lines 70-71) Even though Teng admitted his difficulty with idiomatic word usage, he regarded the ability to develop argument as fundamental in research writing.

Students learned to support argument with empirical data, instead of relying on flowery diction or popular sayings. Chinese students were often taught to use fancy words or rhetoric to convince readers in L1 writing instruction. Jie said that she did not take much effort in data collection or data analysis when she published in Chinese. But in America, they 
learned in a hard way that offering an opinion withoutdata was not persuasive enough. They learned that fancy words or rhetoric can not replace data in verifying claims. For example, Yun learned that the subjective writing style used by many Chinese social science scholarswas not appreciated here. As she commented:

The education and writing assignment we had in China were different from here, especially in the field of arts. The science major might not be that different. The first semester was really hard for me. American professors don't care much about the fancy words you need.... Chinese often write, 'it is obvious that...'. But my professors said that there is nothing in the world that is 'obvious', that we can take it for granted. We need the data to prove it. Chinese tend to use the language rhetoric to convince others, but here they use the data to convince others. This is a big difference.... Chinese writing prefers beautiful, reserved and poetic languages. Research papers in China are more subjective. We don't use much data in China. (lines 46- 65) Yun's comments indicated that traditional Chinese scholarly writing in social sciences did not value empirical data as much as their western counterpart did. Chinese social sciencesscholars, in the old times, tended to write subjectively. Using data to verify one's claims was not valued. Yun's professor told her that there is nothing in the academic world that she can take it for granted. Yun's first semester was tough for her because she did not know what professors expected.

\subsubsection{Challenge in Critical Thinking: Learning to Embrace Diverse Perspectives}

All participants felt challenged yet enjoyed learning critical thinking skills, critiquing authority and their own assumptions. Jie believed that staying open to different perspectives was more important than the fancy language. "We are not English literature majors.... In my field, the most difficult problem is understanding the complex issue." (Jie, lines 22-23) She enjoyed critical thinking, even though this was new to her.

One good thing in academic writing here is critical thinking. In order to write paper, you have to dig into the idea, and know different perspectives about an issue. In China, it tends to be biased. We focus on one group's interest and their standpoint, which you are required to do. Basically you need to be obedient, otherwise you are going to be in trouble. (Jie, lines 58 - 62)

What mattered to Jie was understanding a complex social issue from different perspectives, rather than sticking to one-sided opinion. She thought that Chinese students were taught to believe in one perspective and were not used to analyzing social phenomenon through multiple perspectives. Jie criticized the writing styles she was taught to follow in China as "not frank" and "some model format". As she said,

In China, people do not write very frankly. You are always supposed to write something following certain standards, supporting some "good deeds" and blaming some "bad deeds".... There was always a fixed pattern there. In fact, my Chinese writing is quite good, quite to the standards. But it's not the way I like.

\section{(lines 34-37)}

The prior training to follow a certain format and to support a certain voice caused them challenges in independent thinking. Hong complained that "there is no existing format for her to write literary criticism" in her current program (lines 132-133). Therefore she felt at a loss when shewas encouraged to think independently and creatively. But all of them started to enjoy this freedom of expressing opinions after they got to know the critical expectations of academic writing conventions.

Students also learned to look at their own writing with a more critical lens. They used to write about whatever ideas in their mind. But now they would take time to go to the library, find out exact citations and make a proposal based on literature (Yun, interview). They learned to be accurate in making attributions. They learned to follow scientific steps to collect and analyze data(Fang and Yun, interviews). This critical thinking practice was seen throughout their writing processes, from critiquing literature to justifying new proposals and supporting claims.

In sum, all participants believed that their primary challenge came from their unfamiliarity with the new epistemology assumptions in academic thinking: how to produce, develop and evaluate ideas. They viewed their primary challenge not as linguistic disadvantage, but as lack of preparation for the western ways of thinking in social science research. The following section will explore some sociocultural factors that might cause Chinese EAL writers' lack of preparation in thinking skills.

\subsection{Sociocultural Factors Causing the Challenges}

This group of Chinese EAL students viewed their writing challenges primarily caused by epistemology gaps and lack of rigorous preparation of thinking skills in their prior education.

\subsubsection{Epistemology Gaps in Social Sciences: Subjective and One-Sided vs. Empirical and Open}

First of all, generating new ideas was more "subjective" (Fang \& Yun, interviews) in Chinese traditional scholarly writing. Researchers oftenwrote about their ideas without giving credits to literature. Lack of recognition to others' work is reflected in writing as the loose requirement of citations. For example, Fang said that disciplinary writing in Chinese classical history was not strict with citations or footnotes. After we came to America, we understand that we need to read other people's studies before we start to write. This is a big progress for us". (Fang, lines 69-76) Chinese writers, in the old times, did not see the indispensable function of related literature in verifying a new proposition. Hong alsocommented, "In China, it is impossible to get access to such rich database of previous studies. Many studies you do in China are not up-to-date. You lagged behind the current trends and you were not even aware of that."(lines 161-163)

Secondly, traditional Chinese scholarly writing in social sciences did not value empirical data in verifying argument. The process of developing argumentation was more subjective than the western writing. Empirical data was not regarded as essential in publishing social science research articles in China 
in the old times. Jie recalled that "in the field of education in China, published articles are mostly like summary or literature reviews, with a little bit of your own stand-points."(Jie, lines 42-44). Yun felt that Chinese tend to usefancy words rather than data or facts in persuading others. "Chinese tend to use language rhetoric to convince others, but here they use data to convince others." (Yun, lines 58-59).

Another epistemology assumption gap lies in lack of critical thinking in China's social sciences. Contemporary Chinese scholarly writing in social sciences tend to be "one-sided" (Jie, interview) due to certain sociopolitical reasons. Students were taught to look at a social issue from one perspective."We focus on one group's interest and their standpoint, which you are required to do." (Jie, lines 60-61)

\subsubsection{Test-oriented English Education: Not Leaving Much Room for Teaching Thinking}

Test-oriented English education, which focuses on mastering grammatical knowledge and achieving high scores in multiple choice tests, doesn't leave much space for cultivating students' exploratory thinking skills, as reflected in reading and writing instructional practices. They were notwell-prepared with L1 scholarly writing. Even though all participants passed GRE and TOEFL with high scores, their ability to read, analyze and critique extensive literature was far from meeting graduate study's reading requirement. In general, reading requirement in China's higher education is not as demanding as the western universities.

Teaching advanced thinking skills, such as producing, developing and evaluating ideas, are largely missing in China's English writing instruction. In test-oriented English teaching, the actual training on English writing is usually limited to writing a 200-word essay and following a fixed structure of introduction, body and conclusion. As Liang commented:

In China, I never wrote English essays more than 500 words.... Those English classes were mainly for passing the test, very test-oriented.... In China I didn't write much in English, and when I came here, all of a sudden, I need to write academic paper in English, which is a huge gap for me.... (lines 102-119)

While acknowledging the general lack of academic writing preparation for these Chinese EAL writers, we also need to be aware of the specific historical stage China went through. Many college professors did not receive adequate training in English academic writing. As Ray said,

I think in China, the professors got educated in the time period when the whole education level in China was kind of low. So those professors themselves were not well prepared in academic writing. We didn't have ESL writing class in undergraduate study. The whole college education system in China didn't put too much emphasis on that. So those professors were not strict with our writings. (lines 89 - 93)

In sum, different epistemology assumptions in thinking and insufficient research preparation caused the primary challenges for this group of Chinese EAL writers. Being subjective and lacking critical thinking were two salient features of traditional Chinese social science writing reported by the students. In addition, insufficient academic preparation for research writing skills in the test-oriented education context also contributed to the challenges students encountered.

\section{Discussion}

Based on interview data, I have explored how a group of Chinese social sciencegraduate students viewed their challenges in learning academic writing. All participants regarded epistemology gaps in thinking, rather than the surface language problem, as the primary challenge in academic writing. Sociocultural reasons leading to these challenges include epistemology gaps and lack of academic preparation in research and research writing.

Gee's theory of D/discourses provides a useful theoretical framework for understanding students' writing challenges in specific sociocultural contexts. Each academic discipline functions as a Discourse [10]. Hence each discipline has its own ways of thinking and language use. Chinese students, who were used to subjective and one-sided scholarly writing due to certain sociopolitical factors, need to learn the new "socially accepted ways of thinking, feeling, believing, valuing and acting" ([10], p.131) in their disciplines. The epistemology conflicts between the old and the new Discourses caused them challenges in acquiring the new Discourse [13]. Students' pre-existing sets of epistemology assumptions, cultivated through prior cultural and educational practices, constituted students' 'discursive history' [11].

Although students acknowledged the frustrations of learning the linguistic aspects of the Discourse, they did not view language considerations as the primary concern in research writing. Language use, i.e., the lower-case discourse exists merely as one component within the larger construct of a Discourse [24]. Unlike many EAL students who perceived their writing challenges mainly as surface language problems [2, 28], participants in the study regarded their language challenges not as "terminal'[16], but a developmental issue [26]. Yan and Liang, who were writing qualitative research, certainly felt disadvantaged with their language limitations. But they understood that as long as they kept reading and writing, their language would become better. Yan and Liang did not let their language limitations demoralize them. Instead, they valuedand were confident with their unique perspectives as an EAL writer, similar to Belcher \& Hirvela's study (2005)'s findings [3].

Participants unanimously foregrounded epistemology gaps in thinking as their primary challenge, including students who were doing qualitative research, which usually demands more language use. They believed that their perspectives counted more than the language perse. Used to the subjective and one-sided scholarly writing, Chinese students needed to learn to produce, verify and evaluate ideas with an empirical and critical eye. Students' keen awareness of the epistemology differences might be due to the fact that they were from social sciences, of which epistemology assumptions vary across different sociopolitical contexts. In contrast, Chinese EAL graduate students in sciencesdid not find many epistemology 
challenges in academic writing [28].

Chinese students' epistemology challenges suggest that their prior training of thinking skills was insufficient. It is true that teaching thinking skills have also been traditionally neglected in western education [29] and learning these academic thinking skills can be daunting for both L1 and L2 writers $[1,16]$. However, the current study certainly implies that lack of teaching thinking has been particularly serious in China's test-oriented education system, which did not leave much room for developing students' exploratory thinking skills necessary in research writing. Limited education in thinking skills in social sciences accounted for students' challenges in their disciplinary writing.

This study also shed light on some cultural differences related to verification. Traditional argumentative writing in Chinese tended to rely on flowery diction or rhetoric, rather than the empirical data to support the claims. In their L1 literacy education, writing with exquisitely ornate diction was an important criteria to evaluate their writing ability. Hence, this group of Chinese students move to EAL writing having already acquired the argumentative practices of their native language taught in their L1 educational context [14], which did not give the same weight to hard data as the western academia does. In their L1 education, they were taught to use a different kind of 'reason' and 'evidence' ([34], p. 84) to support their argument. They learned to write argumentatively relying on flowery diction, which is viewed as subjective and unpersuasive in the West [34]. Chinese social sciences academia justifies what is in our minds, whereas its western counterpart needs to use data to justify what is in our minds [37]. Skills of using empirical data, questioning the authoritative opinions and staying open to multiple perspectives were often ignored in their L1 education. Meanwhile, despite the cultural differences in developing argumentation, the study found that EAL writers were adept at and enjoyed learning new values and new ways of thinking during their acculturation processes.

\section{Conclusion}

This study, which explored how eight Chinese social science graduate students viewed their writing challenges, found that the primary challenge was epistemology assumptions gaps and lack of research writing preparation. The epistemology challenges might be traced back to China's scholarly traditions and conventions in the old time. Although the study focused on Chinese students, the pedagogical implications can be applied to EAL students from other cultures. There are several pedagogical implications for EAL writing instructors. First, teachers need to let students understand that perfect grammar is not the only element that makes good writing, and that how to produce, develop and evaluate argumentation is a more fundamental task for constructing solid research writing. English as a foreign language teachers in elementary and secondary education need to be cautious if they focus only on grammar in their language teaching, because the grammar-focused language teaching and learning activities can lead students to pay excessive attention to specific details at the sentence level. In higher education, writing teachers can use journal articles written by established EAL researchers to encourage EAL students that language barrier is not terminal for their academic publication career. Teachers need to develop students' developmental attitudes towards their language limitations and let them understand that linguistic competence will improve as long as they keep practicing. Since the lower-case discourse is also social by nature, teachers need to make it explicit to EAL studentslinguistic features of the Discourse expected by the English-speaking readers.

Second, writing teachers need to foreground discussing epistemology assumptions in thinking underneath the written texts in their day-to day writing instructions. As the study indicates, epistemology assumptions were exactly what this group of Chinese EAL students needed assistance with. What they severely lacked was the rigorous training of doing social science research and research writing. Teachers need to let students compare the disciplinary epistemology and ways of thinking in English research writing with the ones students were educated in their prior sociocultural context, since academic thinking skills might not be valued or valued differently across sociocultural contexts.

This study has limitations that warrant consideration in future studies. First, the participants came from four disciplines in social sciences: education, media studies, library management and American studies. Their writing experiences cannot represent all social science students, such as English literature, which certainly requires higher English language skills. Second, it was only based on retrospective interviews with eight students without examining their writing products. A concurrent analysis of writing products and stimulated recall interviews based on their writing products would provide more details of their writing process and challenges. Another possible direction for future research is to explore established researchers' perspectives on the language problems of EAL students' qualitative research writing. The current study already hinted that professors who were teaching qualitative research actually had greater confidence with their EAL advisee than EAL advisee themselves. More studies can be done to explorehow professors view EAL students' language qualifications in writing qualitative research.

\section{Appendix}

Sample interview questions:

1. Can you talk about your general impression of English academic writing?

2. Can you talk about difficulties or problems you have in English academic writing?

3. Can you give me some specific examples about your problems?

4. As a nonnative speaker of English, how do you see your challenges, if any, in writing qualitative research?

5. What kinds of courses have you taken in academic writing, both in Chinese and in English? 
6. How do you compare Chinese scholarly writings with English ones?

\section{Acknowledgements}

This research project is partially sponsored by Humanities and Social Science Research Funding in Anhui 2015 (SK2015A351).

\section{References}

[1] Atkinson, D. (1997). A critical approach to critical thinking in TESOL. TESOLQuarterly, 31 (1), 71-94.

[2] Bawa, P., \& Watson, S. L. (2017). A phenomenological study of graduate Chinese students' English writing challenges. The Qualitative Report, 22(3), 779-796. Retrieved from http://nsuworks.nova.edu/tqr/vol22/iss3/7

[3] Belcher, D., \& Hirvela, A. (2005). Writing the qualitative dissertation: What motivates and sustains commitment to a fuzzy genre? Journal of English for Academic Purposes, 4, 187-205.

[4] Casanave, P. C. (2002). Writing games: Multicultural case studies of academic literacy practices in higher education. Mahwah, NJ: Lawrence Erlbaum Associates, Publishers.

[5] Chang, Y., \& Kanno, Y. (2010). NNES doctoral students in English-speaking academe: The nexus between language and discipline. Applied Linguistics, 31 (5), 671-692.

[6] Creswell, J. W. (1998). Qualitative inquiry and research designs: Choosing from five traditions. Thousand Oaks, CA: Sage Publications.

[7] Creswell, J. W., \& Brown, M. L. (1992). How chairpersons enhance faculty research: A grounded theory study. Review of Higher Education, 16 (1), 41-62.

[8] Gee, J. P. (1989). Literacy, discourse, and linguistics: Introduction. Journal of Education, 171, 5-17.

[9] Gee, J. P. (1990). Social linguistics and literacies: Ideology in discourses. London: Falmer Press.

[10] Gee, J. P. (1996). Social linguistics and literacies: Ideology in discourses (2nd ed.). London: Taylor \& Francis.

[11] Gee, J. P. (1999). An introduction to discourse analysis: Theory and method. New York, NY: Routledge.

[12] Gee, J. P. (2001a). Learning in semiotic domains: A social and situated account. Unpublished manuscript, Madison, WI.

[13] Gee, J. P. (2001b). Reading as situated language: A socio cognitive perspective. Journal of Adolescent \& Adult Literacy, 44, 714-725.

[14] Hirvela, A. (2017). Argumentation \& second language writing: Are we missing the boat? Journal of Second Language Writing, 36, 69-74. http://dx.doi.org/10.1016/j.jslw.2017.05.002

[15] Hyland, K. (2003). Genre-based pedagogies: A social response to process. Journal of Second Language Writing, $12,17-29$.

[16] Hyland, K. (2016). Academic publishing and the myth of linguistic injustice. Journal of Second Language Writing, 31, 58-69. dx.doi.org/10.1016/j.jslw.2016.01.005

[17] Jones, C., Turner, J., \& Street, B. (1999). Students writing in the university: Cultural and epistemology issues. Philadelphia, PA: John Benjamins Publishing Company.

[18] Langum, V., \& Sullivan, K. (2017). Writing academic English as a doctoral student in Sweden: Narrative perspectives. Journal of Second Language Writing, 35,20-25. http://dx.doi.org/10.1016/j.jslw.2016.12.004

[19] Lea, M. R., \& Street, B. V. (1998). Student writing in higher education: An academic literacies approach. Studies in Higher Education, 23 (2), 157-172.

[20] Li, Y. (2006). A doctoral student of physics writing for international publication: A socio politically-oriented case study. English for Specific Purposes, 25,456-478.

[21] Li, Y. (2007). Apprentice scholarly writing in a community of practice: An "intraview" of an NNES graduate student writing a research article. TESOLQuarterly, 41(1), 55-79. http://dx.doi.org/10.1002/j.1545-7249.2007.tb00040.x.

[22] Li, Y. (2016). "Publish SCI papers or no degree": Practices of Chinese doctoral supervisors in response to the publication pressure on science students. Asia Pacific Journal of Education, 36(4), 545-558. http://dx.doi.org/10.1080/02188791.2015.1005050.

[23] Lillis, T., \& Curry, M. (2006). Professional academic writing by multilingual scholars: Interactions with literacy brokers in the production of English-medium texts. Written Communication, 23(1), 3-35. 10.1177/0741088305283754

[24] MacKay, T. (2003). Gee's theory of D/discourse and research in teaching English as a second language: Implications for the mainstream. 1-28. Unpublished manuscript, University of Manitoba. Retrieved from https://www.researchgate.net/publication/252469631

[25] Matsuda, P. K., Saenkhum, T., \& Accardi, S. (2013). Writing teachers' perceptions of the presence and needs of second language writers: An institutional case study. Journal of Second Language Writing, 22(1), 68-86. doi:http://dx.doi.org.ezp.lib.rochester.edu/10.1016/j.jslw.2012. 10.001

[26] Mohan, B. A., \& Lo, W. A. (1985). Academic writing and Chinese students: Transfer and developmental factors. TESOL Quarterly, 19 (3), 515-534.

[27] National Science Foundation. (2017, June). 2015 Doctorate recipients from U.S. universities. Retrieved fromhttps://www.nsf.gov/statistics/2017/nsf17306/static/report /nsf17306.pdf

[28] Qian, J., \& Krugly-Smolska, E. (2008). Chinese graduate student's experiences with writing a literature review. TESL Canada Journal, 26(1), 68-86.

[29] Ruggiero, V. (1988). Teaching thinking across the curriculum. New York: Harper \& Row, Publishers.

[30] Shang-Butler, H. (2015). Great expectations: A qualitative study of how Chinese graduate students navigate academic writing expectations in U.S. higher education. Unpublished doctoral dissertation, University of Rochester, Rochester.

[31] Shi, L. (2012). Originality of expressions and formal citation practices. Writing and Pedagogy, 4, 43-67. 
[32] Shi, L., \& Yang, L. (2014). A community of practice of teaching English argumentative writing in a Chinese university. System, 42, 133-142.

[33] Silva, T. (1993). Towards an understanding of the distinct nature of L2 writing; The ESL research and its implication. TESOL Quarterly, 27, 657-677.

[34] Stapleton, P. (2017). Ability to argue: Rooted in nature. Journal of Second Language Writing, 36, 83-84. http://dx.doi.org/10.1016/j.jslw.2017.05.007

[35] Strauss, A., \& Corbin, J. (1994). Grounded theory methodology: An overview. In N. Denzin \& Y. Lincoln (Eds.), Handbook of qualitative research (pp. 273- 285). Thousand Oaks, CA: Sage.
[36] Wang, A. (2007). Teaching aviation English in the Chinese context: Developing ESP theory in anon-English speaking country. English for Specific Purposes, 26, 121-128.

[37] Zhang, Z. (2011). A nested model of academic writing approaches: Chinese international graduate students' views of English academic writing. Language and Literacy, 13(1), 39-59.

[38] Zhu, W. (2001). Performing argumentative writing in English: Difficulties, processes, and strategies. TESL Canada Journal, $19(1), 34-50$ 